\title{
First Dorsal Interosseous Muscle of the Hand
}

National Cancer Institute

\section{Source}

National Cancer Institute. First Dorsal Interosseous Muscle of the Hand. NCI Thesaurus.

Code C139198.

A dorsal interosseous muscle of the hand that originates on the proximal half of the lateral border of the index metacarpal and the full length of the medial border of the thumb metacarpal, and inserts into the lateral side of the index finger. 